\title{
FORMACION Y DESARROLLO \\ DE LA INDUSTRIA DE CONSERVAS \\ VEGETALES EN ESPAÑA, 1850-1935*
}

\author{
JOSE MIGUEL MARTINEZ CARRION \\ Universidad de Murcia
}

Ligada al crecimiento económico y al nivel de vida de un país, la industria de conservas vegetales, como otras industrias alimentarias, ha dependido de los cambios operados en la estructura de consumo. Desde hace aproximadamente un siglo, estos cambios han estado determinados por el nivel de industrialización y de servicios, la elevación de la renta per capita, el tamaño y la concentración de población urbana, el desarrollo de nuevos hábitos de compra consustanciales a la sociedad de consumo y, por último, a la participación de la mujer en la población activa, ante el ahorro de tiempo y trabajo que supone la disponibilidad de productos alimenticios manufacturados en el mercado. En España, el impulso de la industria de conservas vegetales se experimenta entre 1890 y la Primera Guerra Mundial, aunque los inicios de la actividad fabril se registran a mediados de la centuria pasada. Sin embargo, los mecanismos que activan su desarrollo en nuestro país son muy débiles. La demanda interna se muestra aún escasa como consecuencia del bajo poder adquisitivo de los consumidores. La demanda externa, por tanto, se configura como motor del crecimiento de este ramo de la industria conservera. Trazar los factores que contribuyeron a la consolidación de este sector, analizar su evolución e incidencia regional -con especial énfasis en la Región Murciana-, es el propósito de este artículo. Pero, antes, me referiré a los avances que en el campo de la técnica se aplicaron a la industria conservera en general durante el siglo xIx, y que tuvieron amplia resonancia en nuestro país.

* Agradezco los comentarios de José Luis Munuera y Santiago Zapata realizados a una versión preliminar de este trabajo, así como la ayuda prestada por M. Angel Pérez. Los desaciertos son de mi exclusiva responsabilidad. 


\section{APLICACION DE LAS TECNICAS DE ESTERILIZACION ALIMENTARIA Y ENVASADO EN LA INDUSTRIA CONSERVERA DURANTE EL SIGLO XIX}

En la segunda mitad del siglo xvin se habian puesto los cimientos de los sistemas de conservación de sustancias perecederas, gracias a las investigaciones de Spallanzini, Gaefer, Scheele, Priestley y Dize, entre otros. Los resultados de sus trabajos experimentales supusieron un avance decisivo en la aplicación del calor a la conservación de vinagre, deshidratación de legumbres y conservación de carnes. Sin embargo, el arte de conservar los alimentos animales $y$ vegetales durante un cierto tiempo tiene su primera concreción en las técnicas ideadas por Nicolás Appert, a comienzos del siglo xIx. Aquellos avances permitieron a Appert su aplicación en pequeña escala, reduciendo a cocción los alimentos introducidos en botellas de vidrio, selladas con tapones de corcho y puestas, por último, en baños de agua hirviendo. Ello ocurría satisfactoriamente en 1810 , en Francia. Al propio tiempo, en Inglaterra, Saddington y Durand daban cuenta de métodos similares, utilizando, además de frascos de cristal, otros envases más variados, como los de hojalata. En ambos casos, y en un primer estadio, las nuevas técnicas de conservación de alimentos encontraron una acogida favorable en los almacenes de suministro de los distintos ejércitos. Pronto se expanden por Europa y América, aplicándose para el consumo de sustancias muy diversas: frutas y verduras, carnes y pescados '.

Las primeras casas de conserva se desarrollaron en Gran Bretaña. Acaso fueron Bryan Donkin y John Hall, en 1813, quienes apreciaron las ventajas de los adelantos y lo pusieron en práctica con fines mercantiles, instalando en Bermondsey la primera fábrica inglesa de conservas. Los resultados no tardaron en llegar: en 1818, el Ejército y la Armada inglesa se abastecían de grandes cantidades de carnes, vegetales y sopa. Por aquellas fechas, incluso las expediciones que se dirigían por el Artico, en busca del paso del Noroeste, llevaban consigo provisiones en conserva. En la otra orilla del Atlántico, los ecos de los nuevos sistemas de conservación llegaron de la mano del industrial William Underwood, quien, en 1817 , se establece en Nueva Orleans, procedente de Inglaterra, con la idea de montar las primeras factorías. La joven república americana disponía de todos los factores que mediaban en el desarrollo de la industria conservera. De un lado, la expansión de la frontera hacia el Oeste y la colonización de grandes tierras vírgenes suponía la creación potencial de un gran mercado de consumo. Por otro, y tal vez en respuesta a la presión de la demanda, se desarrollaron allí gran parte de los adelantos

1 Sobre los inicios y desarrollo de las técnicas de conservación de los alimentos, Derry y William (1977), vol. II; Guzmán Jiménez (1986), pp. 197-202; Parcja Muñoz (1957). 
y perfeccionamientos técnicos que permitieron el crecimiento de la industria conservera en la segunda mitad del siglo pasado. No en vano los Estados Unidos se convirtieron en la primera potencia conservera a fines del siglo XIX, compitiendo incluso con la moderna industria conservera francesa ${ }^{2}$. A diferencia de ésta, la industria americana estaba más diversificada.

La expansión de la demanda y la fragilidad de algunos procedimientos tradicionales de conservación hicieron avanzar notablemente las investigaciones. Ciertamente, la falta de hermeticidad, la insuficiencia del calor aplicado y el deterioro de los productos por la presencia de microorganismos en los alimentos envasados, acarrearon no pocos problemas a fabricantes y consumidores. Estos, a menudo, sufrían trastornos gastrointestinales y aquéllos, a la postre, veían reducir sus ganancas por el descrédito de las mercancías adulteradas. Es por ello que la investigación constituyó, desde un primer momento, un sólido apoyo para la consolidación y el crecimiento de la industria conservera. En este sentido, cabe señalar el adelanto que supuso el cocimiento y esterilización a vapor y presión, patentado por Shriver en Baltimore, en 1874. Los experimentos científicos del químico Luis Pasteur tuvieron bastante que ver con aquello. Con anterioridad, en 1841, otro procedimiento había permitido acortar el proceso de fabricación, al añadirse cloruro de calcio al agua con la que se calentaban los botes. Patentado en Inglaterra, este método permitió un punto de ebullición sustancialmente más alto que el del agua simplemente hervida. De este modo, trabajar con altas temperaturas en menos tiempo supuso un abaratamiento en los costes de producción y, al propio tiempo, un aumento del volumen de producción.

La mecanización y la automatización eran inevitables en el sector conservero si se querían alcanzar cotas de mayor competitividad en un mercado expansivo. Pero las técnicas de enlatado y conservación no sufrieron cambios significativos, pese a ciertas mejoras señaladas, hasta finales del siglo xrx y comienzos del xx. De ahí que los procedimientos tradicionales de conservación de alimentos constituyeran un serio obstáculo al crecimiento de la industria conservera. Hasta 1860 , la fabricación de botes de hojalata era manual, aunque se conocían prensas de remache y máquinas para soldar las junturas laterales. Sin embargo, la automatización de los envases de hojalata con las junturas solapadas y la difusión del tipo moderno de lata abierta por arriba, no se logran hasta 1896-1897, momento en que se patenta en Estados Unidos una mezcla de goma para la juntura perfecta de los extremos de lata (Derry y Williams, 1977).

Pero es a comienzos del siglo xx cuando tienen lugar los más significativos avances tecnológicos aplicados a la conserva. Y ello como consecuencia

${ }^{2}$ Pareja Muñoz (1957), pp. 12-13; Seftel (1985). 
de los avances en el terreno de la bacteriología que se producen a finales del siglo XIX. Sin duda, éstos contribuyeron a perfeccionar los sistemas de conservación de las sustancias alimenticias. Las investigaciones de Pasteur, también en este campo, que demostraban la existencia de microorganismos alteradores de alimentos, fueron determinantes. En 1894, H. C. Rusell, de la Universidad de Wisconsin, constata la presencia de bacterias portadoras de esporas muy termorresistentes en latas de guisantes, corroborando en cierto modo las teorías de Pasteur para las conservas. Al año siguiente, Samuel C. Prescott y otros colegas del Instituto Tecnológico de Massachusetts descubren gérmenes responsables de la alteración del maíz conservado con una deficiente esterilización. Fruto de estos esfuerzos, se desarrolla a comienzos del siglo $\mathbf{x x}$ la denominada conserva sanitaria: consiste en la perfección de los sistemas de cierre a presión por estañado automático, evitando de este modo que la soldadura pudiera deteriorar los alimentos. Asimismo, se establecen tipos diversos de cocción, a temperaturas entre 98 a $103^{\circ} \mathrm{C}$ durante períodos que variaban según los alimentos y el tamaño de los recipientes. Los avances tecnológicos permiten, además, mejorar notablemente la preparación y transformación de los productos envasados. Así, se perfeccionan las máquinas para lavar, deshuesar, pelar, partir y trocear frutas. Y del mismo modo que mejora la manipulación y transformación, también lo hace la parte correspondiente al transporte y almacenamiento. Todo ello no hace sino poner de manifiesto las grandes exigencias de capital que requiere ahora el proceso de producción.

A medida que se amplía la demanda, también se incrementa y diversifica la oferta de productos en conserva. En el último tercio del siglo xix tiene lugar la aparición de la más variada gama de envasados. De nuevo, los Estados Unidos están a la cabeza. Se dan a conocer diferentes botes de sopas, se patenta el maíz cocido (1862), aparecen los primeros purés de tomate conservados (1879) y al natural. Se envasan salmones y langostas, aunque la industria del marisco presentaba todavía caracteres de consumo minoritario. En cambio, encuentran mayor aceptación las conservas de carnes (1870) y la leche condensada. La explotación mercantil de esta última, gracias a los des. cubrimientos de las formas de condensación por Gail Borden, en 1856, iba a suponer un verdadero hito en la industria de conservación de alimentos.

A comienzos del siglo $\mathrm{xx}$ puede decirse que la industria conservera ha alcanzado su madurez. El caso de Estados Unidos es elocuente. Así lo prueba el elevado número de factorías instaladas a lo largo de todo su territorio (de 97 fábricas en 1870 se pasa a 1.813 en 1900), su mecanización, la creciente cantidad de inputs utilizados, y la propia diversificación de los productos elaborados. Finalmente, da fe de ello la constitución, en 1907, de la National Canners Association, agrupación de los conserveros norteamericanos que se propuso, entre otros objetivos, la investigación de nuevos sistemas 
de conservación mediante la instalación de importantes laboratorios. Aunque he tomado como ejemplo el caso de la conserva estadounidense, también en Europa el empuje de la industria conservera es extraordinario. En Gran Bretaña destacan los avances en conservas vegetales; en Francia progresan las conservas de pescado. En ambos países, el consumo de conservas, ya fabricadas in situ, ya importadas (carnes, principalmente), se hace cada vez mayor.

\section{LA INDUSTRIA DE CONSERVAS VEGETALES EN ESPAÑA}

Sobre el desarrollo de la industria conservera española apenas disponemos de información, aunque comienzan a rellenarse algunas lagunas en los últimos años. Recientemente, Jordi Nadal (1987 a) analizaba la situación en la segunda mitad del siglo xIX, comparando por subsectores la ubicación regional de los establecimientos industriales entre 1856 y 1900. Según los datos proporcionados por las Estadísticas de Contribución Industrial y de Comercio, señalaba la ausencia de industrias conserveras hacia mediados del siglo XIX, siendo en su mayoría factorías de salazones de pescado, de tipo artesanal. A comienzos de siglo, la situación había cambiado. El protagonismo parece corresponder ahora a las fábricas de conservas de pescado, carne (éstas en menor medida) y de frutas y hortalizas, si bien la cuota fiscal relativa a los salazones sigue siendo mayoritaria. Como el autor señala, las conservas esterilizadas se presentan, pues, como la modalidad de mayor empuje a la altura de $1900^{3}$.

Por sectores, Xan Carmona ha analizado, para el ámbito gallego, el desarrollo de la industria conservera desde sus inicios, hacia la década de 1820 , hasta su implantación y madurez, que el autor establece hacia 1905-1907 ${ }^{4}$. Como ya es sabido, su localización y formación tenía que ver con la fuerte tradición salazonera existente en Galicia. También las primeras décadas del siglo $\mathrm{xx}$ son testigo en Cantabria de un espectacular crecimiento del sector pesquero-conservero, que se desarrolla en el último tercio de la centuria pasada, según el estudio de Ortega Varcárcel (1986). Sin embargo, de la rama de las conservas vegetales aún no disponíamos de información sobre sus orígenes y formación. Nadal ha mostrado, en el artículo citado, que, en la segunda mitad del siglo xix, aquélla se centra principalmente en La Rioja y Baleares, mientras que en Murcia el desarrollo de la conserva sería más tardío

\footnotetext{
${ }^{3}$ Nadal (1987 a), pp. 32-34.

Carmona Badía (1985), pp. 177-191.
} 


\subsection{Los primeros balbuceos; predominio riojano y balear en el último tercio del siglo XIX}

A mediados del siglo xix se estableció la primera fábrica de conservas vegetales en España. Hacia 1850, José Gutiérrez de la Concha, marqués de La Habana, inició la experiencia industrial en Logroño arrendando a Prudencio Trevijano la finca "Vista Alegre», instalando en ella una fábrica dedicada a la preparación de melocotón al natural para ser exportado a Cuba (Ochagavia, 1955). Cabe señalar que esta región tuvo desde un primer momento ventajas comparativas, al destacar la especialización temprana en árboles frutales ${ }^{5}$, como el melocotón, el albaricoquero y el ciruelo, cuya variedad «claudia», rica en azúcar, lo hace especialmente recomendable para las confituras en conserva. Noticias posteriores confirman la constitución, en La Rioja, hacia 1880-1890, de un núcleo importante de industriales dedicados a las conservas de hortalizas, sobresaliendo en ellas la de pimiento morrón ${ }^{6}$. Por otra parte, en Baleares, la presencia de una temprana industria conservera se relaciona con la abundancia de materias primas; es el caso del albaricoquero, cuya pulpa era elaborada y exportada a Francia y a Gran Bretaña, y también del pimiento rojo. Cabe pensar que, en uno y otro caso, la influencia de norteamericanos. a través de Cuba, en Logroño, y de los franceses, en la isla mallorquina, pudo ser notable en la instalación de los primeros establecimientos fabriles españoles con métodos modernos.

En la última década del siglo xix, La Rioja y Baleares son las dos regiones que destacan en la rama de las conservas vegetales, sobre todo la primera, que, en 1890, concentra 38 factorías de las 64 matriculadas en España, a excepción del País Vasco (véase cuadro 1). La especialización y concentración de esta rama conservera en las regiones mencionadas se acentúa con el cambio de siglo. En 1900 , ambas contribuyen con el 58,3 por 100 de la cuota fiscal por el establecimiento de 70 fábricas, 49 de ellas ubicadas en La Rioja, de las 126 repartidas por la geografía nacional.

En la provincia de Murcia, la actividad conservera se reduce a la presencia de unas pocas fábricas todavía a fines del siglo xIx. Su existencia es casi testimonial, aun disponiendo de ventajas comparativas sobre otras provincias en lo referente a materias primas. Desde mediados del Ochocientos se venía incrementando la superficie de cultivo y la producción de frutas, cítricos y hortalizas. Es precisamente durante los años de la crisis agrícola y en el curso

Sobre la especialización agrícola en árboles frutales y hortalizas en La Rioja, véase el documentado estudio de Gallego Martínez (1986).

- La prensa de fines de los años ochenta se hace eco de cómo, paradójicamente, los murcianos tienen que ir a comprar a La Rioja pimiento en conserva cuando ellos mismos los producen. En Logroño y Haro estaban localizadas estas industrias de pimiento morrón (El Diario de Murcia, 25.11-1888). 


\section{CUADRO 1}

Fábricas de conservas vegetales (frutas y bortalizas) (1) en España (2), $1856-1900$

\begin{tabular}{|c|c|c|c|c|c|c|c|}
\hline & \multirow[b]{2}{*}{1856} & \multirow[b]{2}{*}{1863} & \multirow[b]{2}{*}{1879} & \multirow[b]{2}{*}{1890} & \multirow[b]{2}{*}{1895} & \multicolumn{2}{|c|}{1900} \\
\hline & & & & & & Núm. & $\%$ \\
\hline $\begin{array}{lllllll}\text { Andalucía } & \ldots & \ldots & \ldots & \ldots & \ldots & \ldots\end{array}$ & 1 & 5 & 1 & 1 & 6 & 7 & 5,6 \\
\hline $\begin{array}{lllllllll}\text { Aragón } & \ldots & \ldots & \ldots & \ldots & \ldots & \ldots & \ldots\end{array}$ & - & - & - & 2 & 2 & 6 & 4,8 \\
\hline $\begin{array}{lllllllll}\text { Asturias } & \ldots & \ldots & \ldots & \ldots & \ldots & \ldots & \ldots\end{array}$ & 3 & 6 & 1 & - & - & 1 & 0,8 \\
\hline $\begin{array}{lllllllll}\text { Baleares } & \ldots & \ldots & \ldots & \ldots & \ldots & \ldots & \ldots\end{array}$ & - & - & 1 & 6 & 8 & 21 & 16,7 \\
\hline $\begin{array}{lllllll}\text { Cantabria } & \ldots & \ldots & \ldots & \ldots & \ldots & \ldots\end{array}$ & - & 一 & - & - & $一$ & 一 & - \\
\hline $\begin{array}{lllllllll}\text { Canarias } & \ldots & \ldots & \ldots & \ldots & \ldots & \ldots & \ldots\end{array}$ & - & - & - & - & 2 & - & - \\
\hline $\begin{array}{llllll}\text { Castilla-León } & \ldots & \ldots & \ldots & \ldots & \ldots\end{array}$ & 1 & - & - & - & 2 & 4 & 3,2 \\
\hline Castilla-La Mancha (3) $\ldots \ldots \ldots$ & - & - & - & 6 & 8 & 11 & 8,7 \\
\hline $\begin{array}{llllllllll}\text { Cataluña } & \ldots & \ldots & \ldots & \ldots & \ldots & \ldots & \ldots\end{array}$ & 1 & 1 & 6 & 3 & 6 & 13 & 10,3 \\
\hline $\begin{array}{llllllll}\text { Extremadura } & \ldots & \ldots & \ldots & \ldots & \ldots & \ldots\end{array}$ & - & 一 & - & - & - & - & - \\
\hline $\begin{array}{cccccccc}\text { Galicia } & \ldots & \ldots & \ldots & \ldots & \ldots & \ldots & \ldots\end{array}$ & 1 & - & - & 1 & - & 1 & 0,8 \\
\hline País Valenciano $\ldots \ldots \ldots \ldots \ldots$ & - & - & 2 & 5 & 5 & 8 & 6,3 \\
\hline $\begin{array}{llllll}\text { Región Murciana } & \ldots & \ldots & \ldots & \ldots\end{array}$ & - & - & $\bar{x}$ & 2 & 3 & 5 & 4,0 \\
\hline $\begin{array}{llllllll}\text { Rioja } & \ldots & \ldots & \ldots & \ldots & \ldots & \ldots & \ldots\end{array}$ & - & 8 & 26 & $3 \overline{8}$ & 41 & 49 & 38,9 \\
\hline Total $\ldots \ldots \ldots \ldots$ & 7 & 20 & 37 & 64 & 83 & 126 & 100,0 \\
\hline
\end{tabular}

(1) En 1856 y 1863 , estas fábricas aparecen en la partida dentro de «conservas alimenticias». Es a partir de 1879 cuando se especifica la partida de uconservas de frutas y hortalizass.

(2) La relación de regiones que presento se ajusta a la actual situación dentro del Estado.

(3) Incluye Madrid.

Fuente: Elaboración propia a partir de la(s) Estadística(s) Administrativa(s) de la Contribución Industrial y de Comercio.

de la década de 1890 cuando se expanden los frutales de hueso en los regadíos de los valles del Segura y Guadalentín ${ }^{7}$. En este período, la producción frutícola se destinaba en gran medida a los mercados exteriores, principalmente a Francia. La producción de hortalizas se dirigia, en cambio, al mercado interior. Pero, de todas ellas, el único producto agrícola que generaba cierto valor añadido en los regadíos murcianos era el pimiento para pimentón. Su producción y exportación fue en aumento en la segunda mitad del siglo xix. Utilizado como condimento en las comidas, el pimentón también lo era para la fabricación de productos cárnicos en conserva ${ }^{8}$.

Sin embargo, la primera factoría conservera, con procedimientos moder-

7 Sobre la expansión de estos cultivos en las décadas finales del siglo xIx y primera década del xx, véase Martínez Carrión (1988), pp. 131-160.

8 Aspectos más detallados de ello pueden encontrarse en Martínez Carrión (1987), pp. 558-712. 
nos, que se instala en Murcia data de $1886^{\circ}$. Sus promotores son los señores Museros y Peña. El primero de ellos es bien conocido por las actividades de difusión de la nueva ciencia agronómica desde su cátedra de Agricultura en el Instituto de Murcia. A finales de ese año se constituye la Sociedad Vinícola de Levante, que tiene por objeto, entre otros cometidos, la compraventa y exportación de conservas ${ }^{10}$. El negocio prospera y, en noviembre de 1888 , la factoría amplía la gama de productos vegetales envasados, elaborando a partir de entonces, junto a la producción de frutas al natural en almíbar, pimientos en lata, con bastante aceptación ". En 1900, la actividad fabril de esta empresa continúa ${ }^{12}$, lo que constituye un indicador favorable para las expectativas de la industria conservera murciana. En la década de 1890 se levantan otras cuatro factorías, ampliándose la oferta de productos enlatados. La fábrica de Juan Montesinos, en 1893, se especializa en carne de membrillo y exporta con la etiqueta comercial «La Corona» ${ }^{13}$. En 1895 se instala, a cargo de la firma Pérez y Crech, una factoría «única en la provincia que se halla dotada con los adelantos más modernos conocidos hasta el día”. Dispone de talleres de hojalatería y carpintería y de una máquina de vapor que funciona plenamente en abril de 1896. Toda la fabricación se distingue por la marca «La Murciana». La producción anual se eleva a 600.000 botes, que se comercializa en el mercado interior y en las posesiones de Ultramar ${ }^{14}$. Pero, pese a estos avances, la aportación murciana a la conserva vegetal española es todavía insignificante a la altura de 1900 . Por entonces, la actividad conservera tan sólo adquiría una importante dimensión fabril en Logroño y Mallorca.

\subsection{Cambios en la distribución territorial durante el primer ventenio del siglo $X X$}

En las primeras décadas del siglo $\mathrm{xx}$ se producen cambios muy significativos en la distribución regional. No se discute el predominio riojano hasta la década de 1920, aunque disminuye el número de sus factorías durante la segunda década. En rigor, se pasa del 25,6 por 100 en 1915 a una participación del 13,9 en 1925, sobre 164 y 266 fábricas matriculadas en España, para los años respectivos. La coyuntura que se establece en este período tampoco

- El Diario de Murcia (11-12-1886).

10 Registro Mercantil de Murcia (RMM), Libro 1 de Sociedades (28-12-1886).

"El Diario de Murcia (25-11-1888).

12 Hernansáez (1900), p. 91.

13 Guzmán Giménez (1986), p. 203. Esta firma subsiste actualmente con el nombre de Vda. de Juan Montesinos, en Espinardo, controlada por el Banco Exterior de España con la marca "Coronas".

14 El Diario de Murcia (16-4-1896). 
ha beneficiado a la industria insular. La crisis del subsector conservero en Baleares se hace patente entre 1900 y 1915. Algunos industriales de la isla prosiguen con sus negocios invirtiendo en otras regiones levantinas, como los Esteva, que montan varias factorías desde bien temprano en la cuenca del Segura. El ejemplo es secundado por otras firmas. Y la razón de ello habría que buscarla en la estrategia de los empresarios insulares para minimizar costes, en unos momentos en que la industria conservera comienza a mecanizarse y en la isla escasean las materias primas. En Murcia, además, se produce la variedad «búlida» del albaricoque, de tono dorado y con gran cantidad de azúcar que proporciona una pulpa agradable al paladar de los británicos, grandes consumidores de este artículo. El albaricoque insular, en cambio, es de tono rojizo y con menos cantidad de azúcar, factor éste que incrementa los costes de elaboración de la pulpa, dada la necesidad de añadir más cantidad de este producto. En estas condiciones, no es de extrañar que el número de factorías insulares disminuya y se pase de 21, en 1900, a 6, en 1915.

Se advierte un crecimiento del sector conservero por el territorio peninsular, que corre paralelo con la crisis de la industria balear y con los vaivenes que sufre en La Rioja, prácticamente estancada en las tres primeras décadas del siglo. Por regiones, destacan por el número de fábricas Andalucía, sobre todo en su zona occidental; Cataluña, gran parte de ellas en Barcelona; y País Valenciano, ubicadas más de la mitad en la provincia de Valencia. Estas regiones afianzan su posición hacia 1915. En cuanto a cuota fiscal, tras La Rioja, sobresale Cataiuna, donde las industrias tienen mayor envergadura y presentan algunos adelantos tecnológicos en su aparato productivo. Con cierta timidez, a estas alturas, le siguen las regiones de Castilla-La Mancha, Murcia y Aragón. Pero de éstas habría que destacar Murcia, que la presento en el cuadro como región uniprovincial, y la provincia de Zaragoza.

A lo largo de esta primera quincena del siglo, el desarrollo de la conserva vegetal se apoya en la producción de conservas de legumbres y hortalizas, de frutas al natural y de pulpa de fruta, albaricoque mayormente, en buena medida orientada a la exportación. Pero, de todas estas partidas, el comercio exterior de legumbres y hortalizas logra generar mayores beneficios. Bajo esta partida, las exportaciones de tomate y pimientos eran mayoritarias. Aunque el comercio de pulpa de fruta iba aumentando de manera notable en la primera década de la centuria, su crecimiento espectacular se logra, aunque momentáneamente, al iniciarse la Primera Guerra Mundial. A la mejora del nivel de vida de los países industrializados desde finales del siglo pasado se añaden, ahora, las necesidades de aprovisionamiento de la milicia en combate. La demanda externa se configura como el motor del crecimiento del sector conservero español en este período.

La Primera Guerra Mundial tuvo efectos desiguales en las distintas ramas 
de la industria conservera. En los dos primeros años de la contienda, todos los tipos de producción vegetal se vieron favorecidos. La necesidad de aprovisionamiento alimenticio para los combatientes y la paralización o disminución de la actividad conservera en las regiones productoras afectadas por el conflicto incrementaron las exportaciones españolas. El artículo más favorecido fue la pulpa de fruta, llegándose a exportar 15.103 toneladas en 1915: casi el doble de las partidas del año anterior. Pero, a partir de 1915, el bloqueo de la marina alemana a los países aliados incrementó los costes de transporte, y así se elevaron los precios de la oferta y se deterioraron, a la postre, los niveles de la demanda. Las producciones de frutas al natural y, en particular, de puípa de albaricoque, elaboradas en las regiones levantinas, fueron las más afectadas en el bienio de 1916-1917 (véase gráfico 1). En cambio, experimentaron un auge las exportaciones de conservas de legumbres y hortalizas, dadas las necesidades acuciantes de consumo de los países combatientes.

\section{CUADRO 2}

Fábricas de conservas vegetales en España, 1900-1933

\begin{tabular}{|c|c|c|c|c|c|c|c|c|}
\hline & 1900 & 1905 & 1910 & 1915 & 1918 & 1925 & 1930 & 1933 \\
\hline 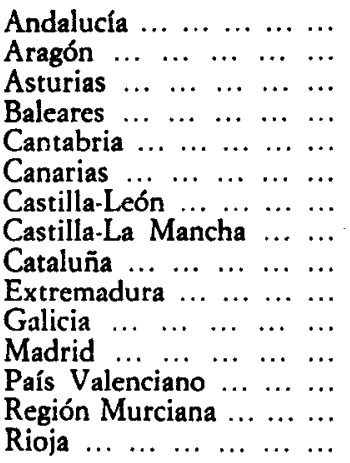 & $\begin{array}{r}7 \\
6 \\
1 \\
21 \\
- \\
- \\
4 \\
9 \\
13 \\
-1 \\
2 \\
8 \\
5 \\
49\end{array}$ & $\begin{array}{r}11 \\
8 \\
1 \\
13 \\
4 \\
4 \\
3 \\
15 \\
7 \\
-\quad \\
- \\
4 \\
14 \\
4 \\
46\end{array}$ & $\begin{array}{r}16 \\
8 \\
1 \\
11 \\
1 \\
-1 \\
12 \\
16 \\
- \\
-3 \\
22 \\
7 \\
58\end{array}$ & $\begin{array}{r}35 \\
8 \\
1 \\
6 \\
1 \\
1 \\
1 \\
9 \\
24 \\
-1 \\
5 \\
20 \\
10 \\
42\end{array}$ & $\begin{array}{r}26 \\
9 \\
2 \\
14 \\
1 \\
- \\
2 \\
8 \\
17 \\
2 \\
-6 \\
27 \\
24 \\
42\end{array}$ & $\begin{array}{r}50 \\
11 \\
1 \\
11 \\
- \\
- \\
4 \\
5 \\
33 \\
2 \\
-11 \\
52 \\
49 \\
37\end{array}$ & $\begin{array}{r}69 \\
13 \\
1 \\
24 \\
- \\
-6 \\
14 \\
43 \\
1 \\
1 \\
12 \\
60 \\
63 \\
47\end{array}$ & $\begin{array}{r}51 \\
13 \\
1 \\
26 \\
- \\
-10 \\
10 \\
9 \\
42 \\
4 \\
1 \\
9 \\
66 \\
97 \\
90\end{array}$ \\
\hline $\begin{array}{ccccc}\operatorname{Total} & \ldots & \ldots & \ldots & \ldots \\
\text { (Indice) } & \ldots & \ldots & \ldots & \ldots\end{array}$ & $\begin{array}{l}126 \\
100\end{array}$ & $\begin{array}{l}134 \\
106\end{array}$ & $\begin{array}{l}156 \\
124\end{array}$ & $\begin{array}{l}164 \\
130\end{array}$ & $\begin{array}{l}180 \\
143\end{array}$ & $\begin{array}{l}266 \\
211\end{array}$ & $\begin{array}{l}354 \\
280\end{array}$ & $\begin{array}{l}419 \\
332\end{array}$ \\
\hline
\end{tabular}

FuENTE: Elaboración propia a partir de los datos de la(s) Estadistica(s) Administrativa(s) de la Contribución Industrial y de Comercio, Madrid. 


\section{GRAFICO 1}

Exportación de conservas vegetales en España, 1907-1935

(Miles de Qm)

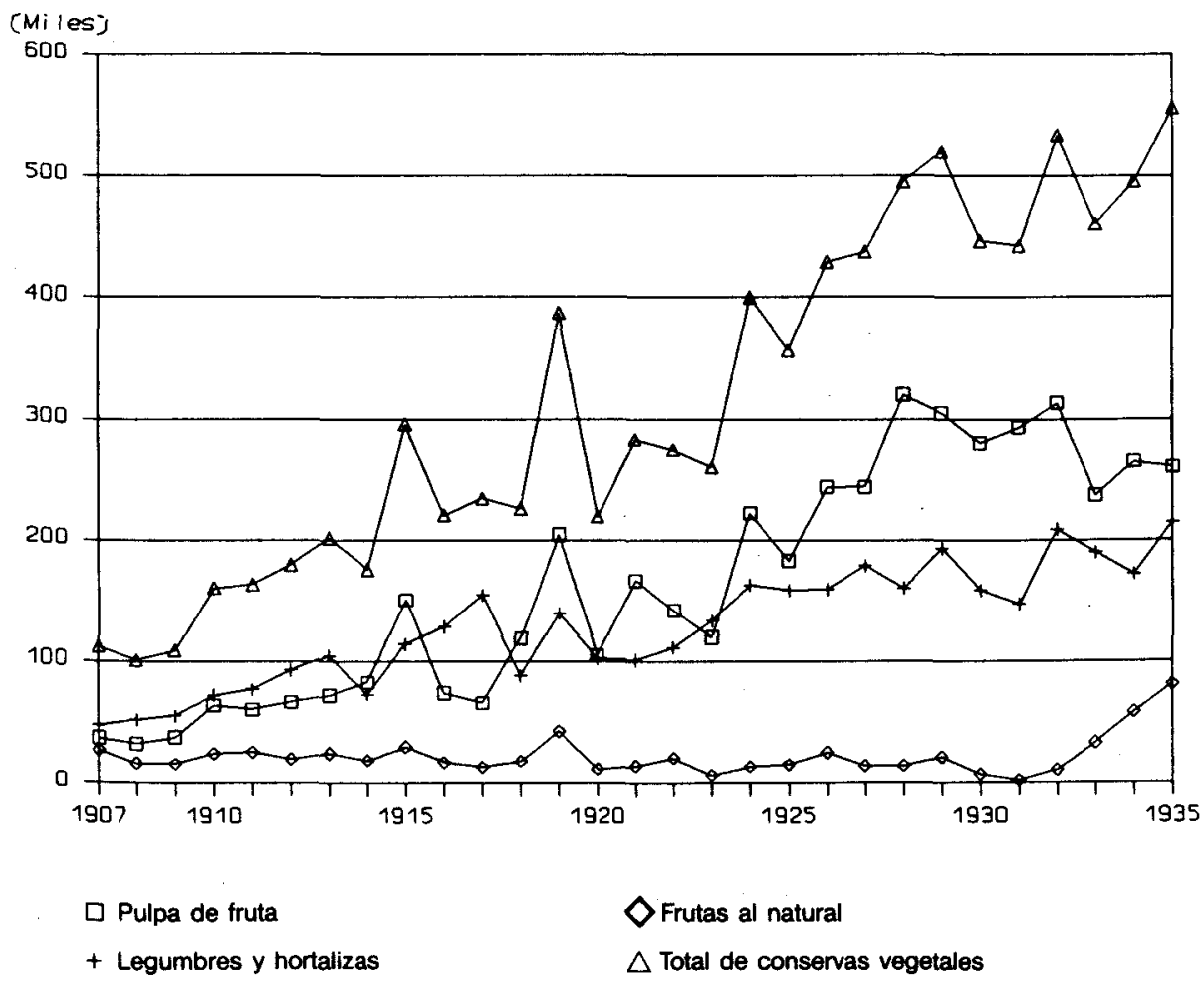

Fuente: Véase cuadro 3.

La llegada de tropas norteamericanas a Europa, la desaparición del bloqueo de los submarinos alemanes en las costas mediterráneas y la mejora de las posiciones bélicas para los países aliados, obligaron a los gobiernos de éstos a un mayor aprovisionamiento de conservas. Ya en 1918, el fin de la conflagración europea aceleró la expansión de la demanda. Pero en este caso el artículo más favorecido fue la pulpa de albaricoque, que se convirtió a partir de entonces en el producto más comercializado de las conservas vegetales españolas. Tras la contienda, y como producto de las circunstancias 
que le rodearon, el sector conservero murciano experimentó un notable crecimiento. En 1915 había 10 fábricas matriculadas, y en 1918 eran 24. Ya en este período, la provincia de Murcia ocupa el segundo puesto, tras Logroño, en el ranking nacional de las conservas vegetales. La guerra habia brindado una excepcional oportunidad para los conserveros españoles y ésta fue aprovechada rápidamente por los industriales murcianos.

\subsection{Consolidación y expansión de la industria conservera en el periodo de entreguerras. \\ El papel del comercio exterior}

La constitución de la Unión Conservera Levantina, en noviembre de 1917, que aglutinaba a 34 fábricas de conserva, nos alerta sobre el grado de madurez de la rama de la conserva vegetal. En rigor, la unión de fabricantes murcianos, junto a conserveros del País Valenciano y La Rioja, tenía como finalidad la consecución de hojatala a mejores precios ante la dificultad de su abastecimiento ${ }^{15}$. Pero, pese a ello, supone el primer paso en la mejora de la organización secterial de la industria conservera. El paso definitivo en la agrupación de los conserveros se daría el 23 de marzo de 1928, al publicarse en la Gaceta la RO por la cual se creaba el Comité Oficial Mixto de Fabricantes de Conservas de Frutas y Hortalizas. Este organismo tendría como fin la coordinación «de los esfuerzos de todos en dirección a propagan. da, busca y creación de nuevos mercados y aunar esfuerzos individuales» ${ }^{16}$. $\mathrm{Su}$ reglamento se aprobó oficialmente por $\mathrm{RO}$ de 23 de agosto del mismo año, y tuvo carácter obligatorio para todos los fabricantes del sector, vieja aspiración de la Asociación murciana. En el Comité Oficial estaban representadas las asociaciones regionales de conservas vegetales más importantes: Asociación Conservera Española (Calahorra), Asociación Conservera de Valencia, Federación de Asociaciones Conserveras (Cataluña y Baleares) y la Asociación Conservera de Murcia (Agrupación de Conserveros de Alicante, Albacete y Murcia). Aquél estaría regido, a su vez, por un Comité Superior, en el que habría dos representantes por cada uno de los organismos mencionados. La actitud del Estado en el apoyo al sector constituye una manifestación más del intervencionismo económico y corporativismo que impregna a la industria española en el curso de los años veinte. Con ello se lograron algunas mejoras en las expectativas empresariales; sin embargo, a diferencia de otras ramas industriales, que dependían de la potenciación de la demanda

\footnotetext{
${ }^{15}$ El Liberal (3-5-1918).

${ }^{16}$ El Liberal (29-3-1928).
} 
interna, la expansión del comercio exterior seguia siendo determinante en el crecimiento de la conserva española.

Ciertamente, la unión de fabricantes de esta rama del sector conservero supuso una mejora de sus posiciones. Gracias a los esfuerzos del Comité Oficial, se consiguieron rebajas en algunos impuestos que gravaban sobre determinados productos. Asimismo, se consiguieron rebajas para la compra de maquinaria empleada, puntas de París, cajas y envases de madera, hojalata en blanco y litografiada. Hasta cierto punto, la labor desempeñada en los años iniciales ocasionó bastante euforia en el sector. Pero, al cabo de dos años, los ánimos se desvanecieron. La vida del Comité Oficial fue efímera y quedó disuelto por RO de 14 de junio de 1930 , a petición de muchos fabricantes que inicialmente se habían aprestado a solicitarlo. En contrapartida, ese mismo año se creó la Junta Central de Conservas de Frutas y Hortalizas, ahora con carácter libre para los industriales. La Junta estuvo encargada de suministrar cuanta información recabase el Ministerio de Economía Nacional para mejorar la producción e incrementar su posición en los mercados internacionales.

En el curso de los años veinte. el incremento de la demanda externa, en particular de Gran Bretaña, explica el aumento del número de factorías que se instalan por el territorio nacional: 266 en 1925 y 354 fábricas en 1930 . El mayor incremento de los productos lo sostiene la oferta de pulpa de albaricoque, cuyas exportaciones clasificadas como pulpa de fruta se duplican entre 1921.22 y 1928-29 (cuadro 3). Al propio tiempo, la mejora en los

\section{CUADRO 3}

Exportación de conservas vegetales. España, 1907-1935

(Promedios anuales)

\begin{tabular}{|c|c|c|c|c|c|c|}
\hline & \multirow{2}{*}{$\begin{array}{c}\text { Pulpa de } \\
\text { fruta } \\
(1)\end{array}$} & \multirow{2}{*}{$\begin{array}{l}\text { Hortalizas } \\
y \underset{\text { legumbres * }}{\text { (2) }}\end{array}$} & \multirow{2}{*}{$\begin{array}{l}\text { Frutas al } \\
\text { natural * } \\
\text { (3) }\end{array}$} & \multicolumn{3}{|c|}{$\begin{array}{c}\text { Números indice } \\
(\text { base }=100: 1907-10)\end{array}$} \\
\hline & & & & (1) & (2) & (3) \\
\hline $\begin{array}{llll}1907-1910 & \ldots & \ldots \\
1911-1915 & \ldots & \ldots \\
1916-1920 & \ldots & \ldots \\
1921-1925 & . & \ldots & \ldots \\
1926-1930 & . & \ldots & \ldots \\
1931-1935 & \ldots & \ldots & \ldots\end{array}$ & $\begin{array}{r}42.830 \\
86.815 \\
113.916 \\
166.969 \\
278.786 \\
273.635\end{array}$ & $\begin{array}{r}56.710 \\
92.567 \\
122.986 \\
133.926 \\
170.345 \\
186.446\end{array}$ & $\begin{array}{l}21.197 \\
24.088 \\
20.863 \\
14.297 \\
16.584 \\
37.135\end{array}$ & $\begin{array}{l}100 \\
203 \\
266 \\
380 \\
651 \\
639\end{array}$ & $\begin{array}{l}100 \\
163 \\
217 \\
236 \\
300 \\
329\end{array}$ & $\begin{array}{r}100 \\
114 \\
98 \\
67 \\
78 \\
175\end{array}$ \\
\hline
\end{tabular}

* En quintales métricos.

FuENTE: Elaboración propia a partir de la(s) Estadistica(s) de Comercio Exterior de Espuña. 
niveles de vida que opera en los países industrializados provoca un incremento cualitativo del consumo alimenticio. Como es lógico, a la diversificación de la demanda corresponde también una diversificación de la oferta. Aunque también parece probable, en más de un caso, que los niveles de sobreproducción alcanzados en algunas cosechas sean responsables de la abundancia de productos vegetales enlatados en los mercados.

Sea por razones de demanda o por motivos de oferta, lo cierto es que a partir de 1923, superada la crisis de reconversión que había supuesto el paso de una economía de guerra a una economía de paz en Europa, los mercados internacionales se inundan de productos agrícolas envasados. En este sentido, los países latinos presentan ventajas comparativas. La oportunidad es bien aprovechada por italianos y españoles, que tienen en Gran Bretaña, Francia y Alemania un importante mercado de consumo. El comercio exterior constituyó un papel económico fundamental en el desarrollo y expansión del sector conservero en la década de los años veinte, aunque esta característica se puede generalizar para todo el período analizado.

A mediados de los años veinte, España domina el mercado internacional de pulpa de albaricoque, producto semielaborado que en Gran Bretaña se utiliza para la fabricación de mermelada. Su consumo se ha generalizado en los desayunos ingleses y comparte la mesa con bacon, huevos y productos lácteos ${ }^{17}$. Puede afirmarse que el 90 por 100 de la pulpa de albaricoque que se recibe en Gran Bretaña es de procedencia española ${ }^{18}$. La oferta francesa, procedente de la Provenza (Avignon, principalmente), que había monopolizado las importaciones inglesas de pulpa a comienzos de siglo, decayó completamente. Ello, en gran medida, se debe a la excelente calidad del

17 Sobre la mejora de la dieta y la composición alimenticia en Gran Bretaña en este periodo, Oddy y Miller (eds.) (1985).

${ }_{18}$ En el curso de los años veinte, la producción de pulpa de albaricoque fue expandiéndose en función de la demanda externa. La ligera disminución de las exportaciones españolas a fines de la década, en 1928-29, no debe explicarse por el aumento de la concurrencia de la oferta de otros países en el mercado inglés, sino por el descenso de los niveles de la demanda de este pais. Aunque hasta el año 1930 no se introduce en las estadísticas oficiales inglesas la partida específica de pulpa de albaricoque, estando hasta entonces englobada en la partida de conservas de frutas, los datos que muestro en el siguiente cuadro evidencian la escasa representatividad de otros países en el mercado inglés (datos en miles de libras).

Procedencia de las importaciones de pulpa en el mercado inglés

\begin{tabular}{|c|c|c|c|c|c|}
\hline & 1926 & 1927 & 1928 & 1929 & 1930 \\
\hline $\begin{array}{llllllll}\text { España } & \ldots & \ldots & \ldots & \ldots & \ldots & \ldots & \ldots \\
\text { EE. UU. } & \ldots & \ldots & \ldots & \ldots & \ldots & \ldots & \ldots \\
\text { Otros paises } & \ldots & \ldots & \ldots & \ldots & \ldots & \ldots\end{array}$ & $\underline{180}$ & $\underline{147}$ & $\underline{111}$ & $\underline{-}$ & $\begin{array}{r}102 \\
4 \\
6\end{array}$ \\
\hline
\end{tabular}

Fuente: Exportación, III, 40, 15 de mayo (1932), p. 14. 
albaricoque, sobre todo del de Murcia, que no tiene rival en los mercados internacionales. Hasta tal punto ha llegado su renombre que muchos conserveros españoles, para obtener un buen precio en el mercado, presentan la oferta de pulpa denominándola «estilo de Murcia», lo que indica el grado de perfección logrado en esa región. Pero, lamentablemente, la producción de mermeladas y confituras en España se encuentra bastante retraída. La causa de que los industriales españoles no aumenten el contingente de pulpa para fabricación de mermeladas in situ, y no generen más valor añadido, reside en la elevada protección arancelaria del azúcar, cuyo precio se mantiene muy por encima de los niveles de precios europeos.

En el campo de las conservas de legumbres y hortalizas, el control del mercado está en manos de Italia, aunque esta rama se encuentra muy desarrollada en los propios paises consumidores. En realidad, tanto Italia como España se habian especializado en la exportación de puré de tomate y tomate al natural. Pero en la producción de puré y pasta de tomate, salsa di pomodoro, los italianos llevaban ventaja suficiente a los industriales españoles. Como puré de tomate, se presenta un producto que resulta de la concentración de la puipa y líquido del tomate maduro, con excepción de pellejo, corazón y semillas, con o sin adición de sal. Como «salsa» o pasta, igual procedimiento, con adición de albahaca y una cantidad mayor de tomate sólido. Las estadísticas de comercio inglés corroboran la importancia de la producción italiana de estos tipos de elaboración en el consumo del mercado británico ${ }^{19}$. Por último, estaban las conservas de frutas al natural, cuya mayor producción correspondía al melocotón en almíbar. Su contribución al comercio exterior fue disminuyendo en el primer tercio del siglo $\mathrm{xx}$ y mantuvo estancada su oferta hasta que se incrementó ligeramente a partir de 1934-35. A diferencia del resto, esta partida adquirirá un gran auge en la década de 1940.

La crisis económica internacional de comienzos de los años treinta afectó a la industria de conservas vegetales, pero no provocó el declive que expe.

${ }^{19} \mathrm{La}$ estructura de las importaciones inglesas de puré de tomate quedaba de la si. guiente manera en el quinquenio de 1926-1930 (datos facilitados en miles de libras):

\begin{tabular}{|c|c|c|}
\hline & Cantidad & $\%$ \\
\hline 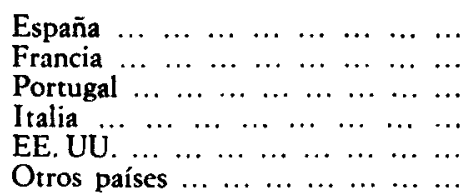 & $\begin{array}{r}143 \\
53 \\
5 \\
578 \\
17 \\
8\end{array}$ & $\begin{array}{r}17,8 \\
6,6 \\
0,6 \\
71,8 \\
2,2 \\
1,0\end{array}$ \\
\hline 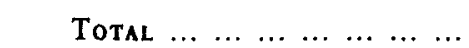 & 804 & 100,0 \\
\hline
\end{tabular}

FUENTE: Exportación, III, 40, 15 de mayo (1932), p. 14. 
rimentaron otros sectores industriales. Por el contrario, en los años 1930-32, la tendencia productiva prosiguió al alza en el caso de la pulpa; se mantuvo, aunque oscilante, en las conservas de legumbres y hortalizas; y sólo disminuyó en las frutas al natural, aunque en este campo las exportaciones españolas habían sido siempre irrelevantes, como ya he señalado. La Estadística de Contribución Industrial muestra incluso un incremento de las fábricas existentes entre 1930 y 1933, que pasan de 354 a 419 en los años respectivos. En este período, al incremento de la demanda exterior de pulpa y otros productos en conserva debe añadirse el aumento de la demanda interna. La caída de los precios de los artículos manufacturados, que afecta también a la producción conservera, y el incremento de los salarios en los dos primeros años de la República ${ }^{20}$, debieron mejorar la capacidad de consumo interior. En general, la pérdida de beneficios empresariales, como consecuencia de la caída de los precios de la oferta, quedó amortiguada por la expansión de la demanda, tanto externa como interna, que favoreció el desarrollo de establecimientos fabriles.

A comienzos de los años treinta, la coyuntura económica supuso un desarrollo de la industria conservera. Sin embargo, lo hizo en favor tan sólo de unas pocas regiones. El crecimiento del producto industrial, deducido del aumento de empresas españolas entre 1930 y 1933, llevó consigo cambios significativos en la distribución territorial. La crisis se manifiesta en Andalucía y Castilla-La Mancha, que en 1933 regresan a posiciones que mantenían en 1925. Por entonces, la provincia de Córdoba destaca, con mucho, del resto de las provincias andaluzas, habiendo arrebatado la primacía que Sevilla mantuvo en las dos primeras décadas del siglo xx. En revancha, las regiones que avanzan, y lo hacen de manera espectacular, son La Rioja y la Región Murciana. En efecto, las provincias de Murcia y Logroño absorben el 44,6 por 100 del total del aparato productivo español, deducido del número de factorías instaladas en su territorio. Ya en este período, Murcia ocupa el primer puesto en el ranking de la industria española de conservas vegetales, mantenido hasta la actualidad. La industria conservera murciana no sólo se ha consolidado, sino que, además, constituye uno de los pilares básicos de la industria de bienes de consumo de la región. La participación de la cuota fiscal de las conservas vegetales en el total regional, en 1933 , es de 9,54 por 100, cuando en 1900 era tan sólo de 0,76 por 100. En España, la contribución de esta rama conservera se situaba en 0,33 por 100 al comenzar el siglo; en 1933, su peso en la estructura industrial era de tan sólo 0,70 por $100^{21}$, a pesar de los progresos obtenidos.

${ }^{20}$ Fontana y Nadal (1980), pp. 119 y 143-144; Tortella (1983), p. 131, y Comín (1987), pp. $128-132$.

23 Para evaluar la participación de la industria de conservas vegetales en la estructura 


\section{EMPRESAS Y EMPRESARIOS. EL CASO DE LA CONSERVA MURCIANA}

Acaso convenga introducir algunas consideraciones sobre la estructura de las industrias y el comportamiento empresarial en la rama que vengo analizando. Para ello no dispongo de más datos y consideraciones que los presentados en mi tesis ${ }^{22}$, por lo que la información estará básicamente relacionada con el sector de la conserva murciana, aunque se pueden extrapolar algunas conclusiones válidas para el conjunto de la rama conservera española. A ellos les agrego cierta información general sobre el grado de difusión de la mecanización en las fábricas de conservas de frutas y hortalizas.

La dimensión de las factorías es, por lo general, pequeña en los primeros estadios de su formación. A fines del siglo XIX, tan sólo destacan algunas firmas comerciales, aunque buena parte de ellas se dirijan a la exportación. En la isla de Mallorca sobresale la casa Esteva, especializada desde bien temprano en la fabricación de pulpa de albaricoque con destino a los mercados exteriores. La factoría de Antonio Esteva y Oliver, primer fabricante conservero de la isla, comienza a funcionar en $1867 \mathrm{y}$, al finalizar el siglo, no sólo es proveedor de la Real Casa, sino que ha conseguido una medalla de oro en la Exposición Universal de París de 1899. Tal es el volumen de pedi. dos en la última década del Ochocientos que los Esteva deciden ampliar el negocio instalando una factoría en la región de Murcia. A tal empeño se dedica su hijo, Juan Esteva Canet, que tras dos años de observación y un intento fallido de instalarla en Orihuela (Alicante), decide finalmente construirla en Alcantarilla. La posición ideal de este pueblo, a unos pocos kilómetros de la capital de Murcia, con buenas instalaciones de fábricas de madera, facilidad de transporte por ferrocarril, abundancia de materia prima y mano de obra, determinan la ubicación de más de una factoría conservera en las primeras décadas del siglo xx. En un principio, la factoría murciana de la familia Esteva provee de pulpa a la empresa mallorquina. Pero, a comienzos del siglo $\mathrm{xx}$, expide directamente sus productos a los mercados de destino. Debió influir en ello la mejora de la capacitación técnica de los empleados, pues inicialmente los envases se fabricaban en Palma, ante la ausencia en Murcia de obreros especializados en soldadura. De este modo, los costes de producción disminuyeron, más aún al ahorrarse los costes de transporte por los envíos de pulpa a la isla. En la primera década del siglo $\mathrm{xx}$

fabril de la Región Murciana y España, he utilizado los datos de las Estadísticas de Contribución industrial y de comercio referentes a los años respectivos. En ambos casos he descontado del total de la cuota fiscal por «fabricación» la parte de cuota correspondiente a las industrias de «gas de alumbrado», «electricidad» y «abastecimiento de aguas potables para el consumo».

${ }_{22}$ Martínez Carrión (1987), pp. 714-735. 
son varias las firmas conserveras mallorquinas que por este motivo, y por la rigidez de la oferta insular ante el crecimiento de la demanda, desmontan sus factorías en la isla y las levantan en las regiones levantinas.

La expansión de la demanda en las primeras décadas del siglo xx debió generar no pocos beneficios. Así se desprende de los datos suministrados por el Libro mayor de la factoría de Juan Esteva Canet, referente a la actividad realizada en 1904. En este libro se detalla el volumen de producción, su valoración y los costes de fabricación, lo que nos da una idea de los beneficios logrados. En dicho año, la factoría de Alcantarilla conseguía una producción de 10.250 cajas de pulpa, cada una de ellas con 10 botes de 5 kilos, que sumaban un total de 512,5 toneladas, cifra muy respetable para la época. La producción se destinaba en casi su totalidad al mercado británico. Otros productos, como los «orellones» de aibaricoque, más propiamente «albaricoque seco", y los botes de tomate pelado al natural, se enviaban al mercado francés, pero los beneficios de la firma comercial se obtenían básicamente con la pulpa de albaricoque. El beneficio neto obtenido en la campaña 1904 es del 25 por 100 . Por ahora, no dispongo de datos posteriores, pero es probable que el margen de beneficios se ampliara en la década de los años veinte, a tenor del incremento de los precios de los productos envasados y la fabricación de botes de hojalata en la región (véase, más adelante, cuadro 5). En este periodo son muchas las fábricas que producen sus propias cajas de hojalata, lo que redujo costes a medio y largo plazo, descontada la amortización inicial de instalación de maquinaria destinada a tal fin.

El aumento de la demanda y las expectativas favorables del negocio conservero hicieron posible que la factoría murciana de los Esteva dedicara gran parte de sus beneficios a la ampliación de la empresa e introducción de maquinaria moderna. En 1905 levanta otra fábrica de conservas y en 1908 adquiere la primera máquina de engrapar, comprada a la casa Ewers de Lubeck. Este hecho demuestra también el carácter pionero de la empresa al comprobar que, por estas mismas fechas, la potente industria norteamericana estaba adoptando ese mismo sistema de cierre. Con la nueva maquinaria, la producción alcanza la cifra récord de 40.000 cajas al año, cuyo valor asciende a 1.200 .000 pesetas, capital que muy pocas empresas españolas de la conserva vegetal movilizan por esta época ${ }^{23}$.

La adquisición de maquinaria moderna y la mecanización de la producción conservera es tarea que lentamente va difundiéndose en la industria. Algunas fábricas emplean el vapor hacia 1890, pero la difusión de motores mecánicos es de comienzos de siglo y adquiere significado en el curso de la década de 1920 (cuadro 4). En 1925, las regiones más adelantadas eran, por

${ }^{23}$ Martínez Carrión (1987), p. 718; Pareja Muñoz (1957), pp. 73-75. 


\section{CUADRO 4}

Fábricas de conservas vegetales que emplean motor mecánico

\begin{tabular}{|c|c|c|c|c|c|c|c|}
\hline & \multirow[b]{2}{*}{1900} & \multirow[b]{2}{*}{1905} & \multirow[b]{2}{*}{1910} & \multirow[b]{2}{*}{1915} & \multirow[b]{2}{*}{1925} & \multicolumn{2}{|c|}{$\begin{array}{l}\text { Mecanización } \\
\text { en } 1925(\%)\end{array}$} \\
\hline & & & & & & (1) & $(2)$ \\
\hline 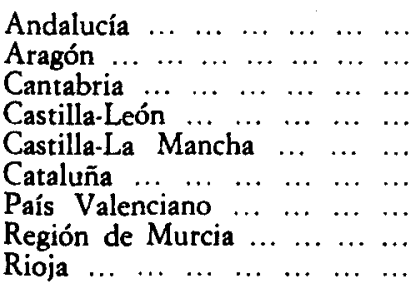 & $\begin{array}{l}- \\
- \\
- \\
- \\
-\end{array}$ & $\begin{array}{l}\bar{z} \\
\overline{1} \\
\overline{-} \\
\overline{1} \\
-\end{array}$ & $\begin{array}{l}\frac{1}{1} \\
\frac{1}{1} \\
6 \\
1 \\
2\end{array}$ & $\begin{array}{l}1 \\
1 \\
1 \\
1 \\
4 \\
4 \\
2 \\
3\end{array}$ & $\begin{array}{r}21 \\
1 \\
1 \\
1 \\
4 \\
1 \\
12 \\
33\end{array}$ & $\begin{array}{r}42,0 \\
9,0 \\
-25,0 \\
6,2 \\
12,1 \\
1,9 \\
24,5 \\
89,2\end{array}$ & $\begin{array}{r}28,4 \\
1,3 \\
\overrightarrow{1,3} \\
1,3 \\
5,4 \\
1,3 \\
16,2 \\
44,6\end{array}$ \\
\hline Total $\ldots \ldots \ldots \ldots \ldots$ & 1 & 2 & 13 & 17 & 74 & 27,8 & 99,8 \\
\hline
\end{tabular}

(1) Porcentaje sobre el total de fábricas en cada región.

(2) Porcentaje sobre el total de fábricas mecanizadas en España.

FurNTE: Elaboración propia a partir de los datos de la(s) Estadística(s) Administrativa(s) de la Contribución Industrial y de Comercio, Madrid.

este orden, La Rioja, Andalucía, Murcia y Cataluña. Pese a estos avances, que en algunas provincias son muy notorios - tal es el ejemplo de La Rioja-, buena parte de la industria conservera reposa sobre pequeñas factorías, que hacen un uso intensivo del factor trabajo. Las inversiones en capital fijo no son cuantiosas ${ }^{24}$, si se exceptúan algunas empresas instaladas en las regiones que presentan ventajas comparativas. De hecho, la mecanización afecta en 1925 al 27,8 por 100 de las fábricas españolas.

La causa de este relativo atraso en la mecanización de la conserva vegetal reside en su carácter estacional y en la propia composición de la oferta. Hacia 1930 , la industria estaba especializada en productos con poco valor añadido, pulpa principalmente. La producción de confituras y mermeladas había aumentado, pero todavía encontraba dificultades por la fuerte protección arancelaria que sostenía el azúcar. Con unos precios para el azúcar de los más elevados de Europa ${ }^{25}$, la empresa conservera no tenía incentivos para incrementar la

2 Sobre estos aspectos, José Bellver, «La crisis conservera murciana. Atraso y descrganización», artículos aparecidos en El Liberal (11-1-1928 y 29-3-1928).

${ }^{25}$ La elevada protección arancelaria sostenida en el azúcar español, en Jiménez Blanco $(1986$ b) y Biescas Ferrer (1984). 
oferta de productos más elaborados y que requerían cierta mecanización. Los progresos en el campo de las confituras y mermeladas no son destacados, pues en ningún momento la relación de fábricas alcanza la quinta parte de la conserva. En 1900, de 126 fábricas, 14 emplean azúcares. En 1918 son 23 sobre un total de 180 factorías. Y en 1933, el número asciende a 72 , es decir, un 17,2 por 100. Su importancia tan sólo radica en Murcia, Córdoba, Logroño y Valencia. Obviamente, el empleo de azúcar en la conserva va a depender de la especialización productiva existente en cada una de estas regiones, habida cuenta que en las hortalizas no se utiliza.

En cuanto a la mecanización de la industria auxiliar de fabricación de cajas de hojalata, el empleo de motores mecánicos, en 1930, es prácticamente total en la región de Murcia, La Rioja, Aragón, Cantabria, Cataluña y Castillas, mientras que hay una relación mayor de procedimientos manuales y tradicionales en Andalucía, Asturias, Galicia y País Valenciano (cuadro 5). A comienzos de siglo predominaban los métodos de soldadura manuales, hecho que era común al conjunto de la industria conservera española, incluida la del pescado ${ }^{26}$. Es curioso que la fecha de adquisición de maquinaria moderna para la soldadura en el enlatado por la factoría murciana de los Esteva, 1908, coincida con las disposiciones francesas que reglamentan la industria conservera del país vecino. En Francia se aconseja, a partir de entonces, que se emplee únicamente hojalata estañada al estaño fino, practicar la soldadura interior de las latas sin mezcla de plomo y, por último, que en la composición de la pintura exterior de la lata no entrara cantidad alguna, por pequeña que fuera, de productos derivados del plomo ${ }^{27}$. Ese mismo año, el Consejo Superior de Higiene Pública galo llama la atención sobre los peligros a que se expone el consumidor por el uso de conservas alimenticias contenidas en cajas pintadas o barnizadas exteriormente con material a base de plomo. La reacción del gobierno francés es inmediata. En diciembre de 1908 queda prohibida en territorio galo la fabricación y circulación de cajas de conservas con las características aducidas, dando un plazo de tiempo para que las fábricas pudieran adaptarse a las nuevas normativas, que entrarían en vigor el 1 de agosto de $1909^{28}$. Dada la vinculación de la oferta española con la demanda francesa y extranjera, los empresarios debieron mejorar a partir de entonces los sistemas de envasado, introduciendo la soldadura mecánica en muchas de las fábricas y sustituyendo el plomo por el estaño fino. Estos factores implicaron un incremento de los costes unitarios de producción para el conjunto de la industria conservera.

\footnotetext{
26 Carmona (1985), p. 183.

${ }^{27}$ El Liberal (7-8-1908).

${ }^{28}$ El Liberal (11-12-1908).
} 


\section{CUADRO 5}

Fábricas de cajas de hoja de lata para conservas en España, 1900 y 1930

\begin{tabular}{|c|c|c|c|c|c|c|c|}
\hline & \multicolumn{3}{|c|}{1900} & \multicolumn{4}{|c|}{1930} \\
\hline & \multirow[b]{2}{*}{ Fábricas } & \multicolumn{2}{|c|}{ Prensas } & \multirow[b]{2}{*}{ Fábricas } & \multicolumn{2}{|c|}{ Prensas } & \multirow{2}{*}{$\frac{\%}{(3)}$} \\
\hline & & (1) & (2) & & (1) & $(2)$ & \\
\hline 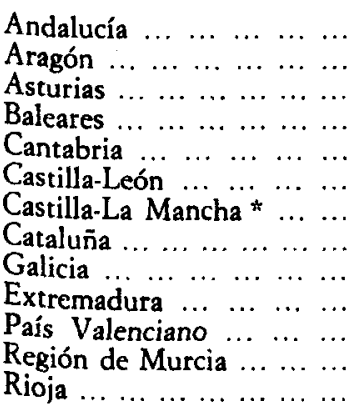 & $\begin{array}{r}6 \\
2 \\
4 \\
1 \\
5 \\
- \\
10 \\
8 \\
4 \\
1 \\
1\end{array}$ & $\frac{\frac{4}{2}}{\frac{3}{3}}$ & $\begin{array}{r}13 \\
4 \\
4 \\
1 \\
9 \\
- \\
11 \\
10 \\
9 \\
1 \\
1\end{array}$ & $\begin{array}{r}52 \\
7 \\
27 \\
2 \\
14 \\
1 \\
7 \\
26 \\
46 \\
1 \\
39 \\
30 \\
33\end{array}$ & $\begin{array}{r}44 \\
7 \\
12 \\
1 \\
14 \\
1 \\
9 \\
36 \\
51 \\
30 \\
35 \\
28\end{array}$ & $\begin{array}{r}65 \\
7 \\
27 \\
2 \\
14 \\
1 \\
9 \\
46 \\
67 \\
1 \\
44 \\
35 \\
35\end{array}$ & $\begin{array}{r}18,8 \\
2,6 \\
6,4 \\
0,5 \\
5,1 \\
0,2 \\
2,6 \\
14,8 \\
17,0 \\
0,2 \\
13,9 \\
11,0 \\
7,4\end{array}$ \\
\hline Total $\ldots \ldots \ldots \ldots$ & 42 & 16 & 60 & 285 & 269 & 353 & 100,0 \\
\hline
\end{tabular}

* Incluye Madrid.

(1) Juegos sencillos de prensas movidos mecánicamente por agua o vapor.

(2) Id. movidos por caballerías y a mano.

(3) Participación $(\%)$ regional de la cuota fiscal de fabricación de cajas de hoja de lata para conservas en España (a excepción del País Vasco).

FUENTE: Elaboración propia a partir de la(s) Estadistica(s) Administrativa(s) de la Contribución Industrial y de Comercio, Madrid.

Sobre la financiación de la industria conservera y las conexiones con otras actividades productivas, las relaciones que se establecen con sectores sociales vinculados al comercio y la agricultura son bastante estrechas en el caso murciano. $\mathrm{La}$ interacción entre el sector agrario y el industrial me parece crucial para entender, en general, todo el proceso de industrialización en esta región. Pero las inversiones de capital suelen ser modestas, dada la naturaleza de la industria conservera, aunque existen casos excepcionales de algunas firmas comerciales. Aunque en los inicios cobra importancia la aportación de capital mallorquín, el grueso de la industria murciana se nutre de capital autóctono que proviene de negocios relacionados con el control de los circuitos de comercialización de frutas al extranjero, de sectores sociales ligados a la propiedad de la tierra y, en menor escala, de empleados y dependientes y 
de algunos industriales y profesionales. Hay constancia de los vínculos de la conserva con los primeros grupos socioeconómicos, propietarios de la tierra y comerciantes, en las numerosas fábricas que se construyen en la Vega Media del Segura, a lo largo del período histórico analizado.

También hay que reseñar la presencia de capital extranjero. En 1906, la firma francesa Champagnes et Frères Limited, domiciliada en París, levanta dos fábricas, una en Alcantarilla y otra en Abarán. La firma quiebra y se hace cargo de los negocios otra casa francesa, F. Vignatié Successeur, de Burdeos, proveedor de envases de Champagnes et Frères, pero en asociación con capital español. En 1914 tenía como director a M. Abel Agostini, con residencia en Marsella. El representante en Alcantarilla era Francisco Esteve, mientras el de Abarán era Joaquín Velasco, que con el francés formaban la trinidad de la sociedad, que no estaba registrada en Murcia. La fábrica de Alcantarilla era una de las de mayor envergadura de la región. Trabajaban en ella cerca de 1.000 empleadas en temporada alta, repartidas en 50 grandes mesas bajo los cobertizos laterales de la empresa, con sus correspondientes máquinas para partir y deshuesar la fruta. Existía una sección donde las operarias clasificaban las mercancías y las separaban por clases y una sección de máquinas, con calderas, calderines, jaulas y serpentinas. En el interior, la fábrica disponía de un taller de hojalatería para fabricación propia de botes y envases. La entrada de fruta en 1914 contaba con la sorprendente cantidad de 18,5 y 21 toneladas diarias de albaricoque; y, en la temporada del melocotón, de 9,5 a 10 toneladas diarias. La zona de compras de la fruta abarcaba desde Cieza hasta Librilla y Beniaján. El número de empleados fijos, con predominio de mujeres, a lo largo de todo el año era de 200 aproximadamente ${ }^{29}$. En noviembre de 1921 se hizo cargo de la factoría de Alcantarilla el grupo suizo de conservas alimenticias Leuzbourg, antes Heuckell, S. A., representado por el ingeniero y súbdito suizo Gerald Eberhard, que, junto con capital español, en manos del también ingeniero Leonardo Rodríguez Díaz, entonces diputado a Cortes y residente en Madrid, formaron la sociedad anónima HeroAlcantarilla. La sociedad quedó constituida en Madrid el 20 de enero de 1922 y fijó su domicilio social en Alcantarilla. El capital reunido para su instalación había sido de 600.000 pesetas, repartidas en 600 acciones nominativas, emitiéndose también, como otra fuente de financiación, 1.000 obligaciones por valor de 1.000 .000 de pesetas ${ }^{30}$. Por entonces debió constituir en España una de las fábricas de mayor envergadura. En la actualidad, la firma comercial Hero forma parte de uno de los grupos internacionales de más prestigio en el ramo de las conservas vegetales.

29 El Liberal (12-4-1914)

${ }^{30}$ Registro Mercantil de Murcia, Libro de Sociedades Mercantiles, núm. 33, f. 42. 
La participación de capital extranjero en la conserva murciana no se agota con este ejemplo. En 1911, otro súbdito francés, Federico Vallette Fourcade, domiciliado en Alcantarilla, junto con Luis Fernández Molina, propietario agrícola de Blanca, constituyen en Murcia la sociedad «en comandita de Federico Vallette». En el Raal, pedanía de huerta de la capital, y en la finca propiedad del segundo, titulada Villa Luisa, se levanta la fábrica, gestionada y dirigida por el primero. El capital tan sólo asciende a 60.000 pesetas. Otro caso de participación de capital francés se advierte en la sociedad anónima La Totanera, que se constituye el 25 de junio de 1913, pero años más tarde queda en manos del capital autóctono. Exclusivamente orientada al negocio conservero, esta fábrica, instalada en Totana, elabora diariamente, en 1917, ahora bajo la sociedad García Martínez y Cía., del orden de 30 a 40 toneladas diarias de conserva de albaricoque, melocotón y tomates. $\mathrm{La}$ fábrica tiene en su haber dos calderas de vapor de $60 \mathrm{CV}$, y en temporada alta ocupa a más de 300 operarios, mujeres en su mayoría ${ }^{31}$. Más importante por el monto de capital invertido, que asciende a medio millón de pesetas, es el arriendo que se hace, en 1925, de la fábrica del ingeniero cartagenero José Bellver Mustieles, la Industrial Cítrica Murciana, en Alcantarilla, por la sociedad anónima Moser y Macey, de capital inglés, para la fabricación de conservas y ácido cítrico. Sin embargo, aun a la importancia inicial de financiación de capital extranjero y mallorquín o área de influencia catalana, se advierte un claro predominio del capital social autóctono. Este se muestra vinculado a la esfera de la producción y circulación del sector agrario en el primet tercio del siglo $\mathrm{xx}$, sobre todo en su etapa de consolidación.

Por último, hay que referirse a los efectos de arrastre inducidos por la industria conservera, que afectan a la esfera de la producción industrial y al ámbito de la producción agrícola. Por un lado, la influencia se ejerció sobre la fabricación de envases metálicos. A la altura de 1930, muchas factorías conserveras elaboraban sus propias necesidades de botes de hojalata para el envasado de la producción, disponiendo de talleres propios para tal fin. Pero también se levantan fábricas de envasado metálico que no tienen relación directa con los agentes sociales de la conserva. En definitiva, se advierte que en las zonas de tradición conservera predomina esta rama de fabricación (cuadro 5). En Murcia, ya en los primeros pasos de la conserva, destaca la instalación de la Industrial Murciana, S. A. Esta sociedad se constituye en febrero de 1906, con un capital de 200.000 pesetas $^{32}$. En 1908 elabora envases para membrillos $y$, muy especialmente, para el consumo de factorías de pimentón y conservas. La fábrica no se limita al envasado; también se

El Liberal (8-4-1917).

${ }^{32}$ RMM, Libro de Sociedades, núm. 22, f. 566. 
especializa en el dibujo, estampación y grabado de las marcas comerciales, manteniendo una férrea competencia con otras firmas españolas de su clase. La empresa murciana domina, por entonces, los mercados de Murcia, Albacete y parte de Alicante ${ }^{33}$. Pero los conserveros debieron soportar elevados costos en la producción final hasta bien entrado el siglo $\mathrm{xx}$. Las dificultades de aprovisionamiento de hojalata para envasado a causa de los elevados aranceles supuso enormes dificultades para el sector hasta comienzos de los años veinte, pese a los esfuerzos señalados. Su situación mejoró al final del período analizado, cuando la mayor parte de las factorías confeccionaban sus propios envases ${ }^{34}$.

Conjuntamente con otras industrias agrarias y la creciente comercialización de productos agrícolas frescos, la conserva potenció la industria de la madera. El aumento de sus exportaciones desde finales del siglo pasado, al igual que ocurre en el País Valenciano ${ }^{35}$, estimuló el desarrollo de fábricas de cajas y embalaje de madera. No en vano, en la relación de costes de la campaña 1904 realizada por la factoría de los Esteva, los gastos por la utilización de 10.631 cajas de madera de envase suponían la tercera partida más importante, tras la fruta fresca, que ocupaba, como es lógico, el primer lugar, y las cajas de hoja de lata. En términos globales, en 1900, el sector de la madera participaba con un 2,5 por 100 en la estructura fabril de la provincia de Murcia. Desde entonces no cesó de aumentar, y de manera muy notable. En 1915, su cuota porcentual era de 8,4 ; en 1930 alcanza el 12 por 100 y aún en 1933 logra el $14,1^{36}$. Además de la fabricación de envases metálicos y la madera, la industria incentivó la demanda de papel para etiquetas y la confección de envases litografiados. Por otro lado, cabe señalar el impulso que recibieron diversos sectores relacionados con la mecanización de la conserva: instalación de vapores y calderas, talleres de reparación y montaje y, entre otros, el aumento de las instalaciones frigoríficas de gran capacidad para la conservación de las materias primas, aunque sólo disponían de ellas las grandes factorías.

Pero, de todos los sectores productivos, la agricultura fue la más bene-

${ }^{33}$ El Liberal (8-9-1908).

${ }^{34}$ Es cierto que los conserveros disfrutaban de algunas ventajas si exportaban sus productos con hoja de lata elaborada por ellos mismos. En ese caso se les concedía la devolución de derechos de aduana. Por ello, las grandes empresas conserveras disponían de talleres propios para fabricar envasado. Pero las devoluciones se retardaban, al hacerse por RO, y ello ocasionaba desembolsos a largo plazo. Es por ello que en 1921 se suceden las manifestaciones pidiendo entrada libre de hoja de lata para que pudieran beneficiarse todos los productores de conservas de frutas (El Liberal, 6-12-1921).

${ }^{3}$ El avance del sector de la madera en el Pais Valenciano durante la segunda mitad del siglo xix ha sido señalado por Nadal (1987 b), pp. 128-129. Con anterioridad, aunque para el tercer cuarto del siglo, por Azagra Ros (1982).

36 Martínez Carrión (s. f.). Datos relativos presentados en un trabajo, inédito, sobre el proceso de industrialización en la región murciana. 
ficiada. El incremento de la demanda de frutas y hortalizas expandió el área de cultivo y posibilitó la mejora de las variedades de los productos envasa. $\operatorname{dos}^{37}$. No hay que olvidar tampoco que en Murcia buena parte del capital social conservero estaba directamente relacionado con el sector agrario, al ser propietarios de la tierra. En numerosas factorías que se levantan en Abarán, Blanca, Alcantarilla y en la Huerta de Murcia, su presencia se encuentra bien documentada. Ya en las primeras décadas del siglo xx hay bastantes casos de industriales conserveros que invertian en la compra de tierras. De este modo, los empresarios disponían de una parte de la materia prima que ellos mismos transformaban. Finalmente, como he señalado, la industria incentivó la mejora y selección de las variedades. Es de sobra conocida la influencia que ejerció sobre la demanda de albaricoque el tipo «búlida», cuyas excelentes cualidades conquistaron mercados internacionales. Así también ocurrió con la variedad tomatera denominada «sangre de toro». Por su calidad, color intenso y formato de pera, nombre con el que se le conoce popularmente, encontró gran predilección en los mercados exteriores ${ }^{38}$. En 1930, de esta variedad se exportaban aproximadamente unas 500.000 cajas de tomate al natural, equivalente a una producción anual de 15.000 toneladas. Un ejemplo que ilustra todo ello lo encontramos en el industrial mallorquín Esteva Canet, ya afincado en Murcia, y cuya empresa familiar todavia hoy persiste. A comienzos de siglo, establecido en Alcantarilla, adquiere unos terrenos de secano y planta en ellos 20.000 árboles de albaricoquero. Entre sus logros, unificó variedades y consiguió resultados excelentes en la calidad de la fruta. Pero, al cabo de unos años, las plantaciones conocieron la plaga del albaricoquero conocida como «barrera». El industrial, ahora también agricultor, envió troncos enteros al Instituto Pasteur de París y a California. Los resultados de las investigaciones no fueron del todo claros y optó por arrancar los plantíos de albaricoque, sustituyéndolos por almendros y algarrobos ${ }^{39}$. Ejemplos como éste, de industriales que canalizaron parte de sus recursos hacia la agricultura, debieron multiplicarse a lo largo del período, revalorizando con ello la producción de la tierra.

${ }^{37}$ La mejora de las variedades de determinados cultivos y el incremento de la producción agrícola en diversas regiones, especializadas en la conserva, puede verse en Calatayud Giner (1986), Garrabou (1985), Gallego Martínez (1986), Jiménez Blanco (1984), Martínez Carrión (1987), Pujol (1988) y Zapata Blanco (1986). A escala nacional, Jiménez Blanco (1986 a).

is Así se advierte en los informes oficiales de los industriales conserveros: «su sabor agradable y su aroma riquísimo hacen del tomate murciano el predilecto de los mercados». Industria y Comercio, XX, 14, mayo 1931, p. 9.

${ }^{39}$ Pareja Muñoz (1957), pp. 74.75. 


\section{CONCLUSIONES}

En primer lugar, hay que resaltar que el fuerte impulso que registra la incuustria de conservas vegetales en las primeras décadas del siglo $\mathrm{xx}$ deriva de la expansión de la demanda proveniente de los mercados exteriores. Gran Bertaña se convierte en nuestro principal cliente, con mucha diferencia del resto, Francia y Alemania, por este orden. La demanda interna se muestra débil por causas bien conocidas: bajos niveles de renta por habitante en comparación con los países industrializados, y también por el encarecimiento de la oferta, que en algunos casos comporta elevados costes que gravan sobre el consumo. Sólo al final del período, el consumo interior de conservas adquiere cierto significado. El incremento de los ingresos familiares y la urbanización debieron provocar cambios en las pautas alimenticias de los consumidores: en 1935 , el mercado nacional absorbe el 20 por 100 de la producción elaborada en la región de Murcia, cifra nada despreciable si se tiene en cuenta que en 1970 el mercado interior tenía una cuota del 29 por 100 sobre el total de la producción española.

No obstante, hay que hacer constar que en la demanda de conservas vegetales influye, además de su precio y el nivel de renta, la disponibilidad y el precio de los productos frescos. El hecho de que el nivel de consumo interior de conservas en España sea bajo es imputable, en gran medida, a la posibilidad de los consumidores españoles de obtener productos hortofrutícolas frescos en buena parte del año. Además, pese a que los productos frescos son perecederos y alteran sus características fácilmente con el tiempo, existe una baja elasticidad de sustitución entre la mayor parte de las conservas y sus correspondientes productos frescos. Por otro lado, el consumo de conservas vegetales forma parte de determinadas pautas culturales, y ello condiciona los hábitos alimenticios que tradicionalmente han existido en los pueblos mediterráneos.

Dejando a un lado los aspectos de la demanda, conviene señalar los principales rasgos de la estructura de las empresas y de la oferta. En cuanto a la primera, se advierte la inexistencia de economías de escala. La industria de conservas vegetales se caracteriza por su atomización en pequeñas y medianas factorías, aunque sobresalen algunas de dimensiones importantes. En consecuencia, existe una gran diversidad de marcas y firmas comerciales. La ausencia de concentración empresarial no ha sido obstáculo, sin embargo, para mantener la competitividad de la oferta española en los mercados internacionales. Esta se ha basado siempre en la calidad de las frutas y en los precios bajos. Con toda probabilidad, la ausencia de concentración empresarial ha restado capacidad financiera a la hora de introducir mecanización adecuada y, de existir, hubiera elevado la participación de los productos acabados 
en las exportaciones totales de conservas vegetales. Ello hubiera reducido un porcentaje considerable de semielaborados - la pulpa de albaricoque, especialmente-, y hubiera supuesto un aumento del valor añadido del sector al incrementarse la producción de mermeladas y confituras. Aun así, y pese a niveles de productividad bajos - la mayoría de las factorías reposan en el uso intensivo del factor trabajo-, la industria conservera española, y en concreto la murciana, se muestra dinámica y adaptable a las necesidades de la demanda. Ya en torno a 1930, la mecanización en determinadas ramas de la conserva vegetal se encuentra àvanzada en algunas regiones: Rioja, Andalucía y Murcia.

Por otra parte, no parece que resultaran muy eficientes las grandes instalaciones fabriles, teniendo en cuenta la temporalidad de los trabajos y los imperativos impuestos por las materias primas en los lugares de producción. La estacionalidad de los productos frescos, su inmediata elaboración y la necesidad de alternar una gama de productos con otra, no requería, la mayoría de las veces, ni grandes instalaciones ni tampoco grandes capitales. En cuanto a la mano de obra, el volumen de participación se muestra bajo en relación al total de la población ocupada. En cada fábrica, sólo un porcentaje mínimo, varios operarios especializados, permanecían fijos a lo largo del año, además del personal de administración y dirección de la empresa. En cambio, durante la época de máxima actividad - meses de verano- se ocupaban a varios centenares de operarias, alcanzando incluso el millar en las factorías más importantes. Durante la campaña se movilizaban grandes contingentes de mano de obra femenina y, en algunas ocasiones, se hacía necesario recurrir a fuerza de trabajo de pueblos limítrofes. Las mujeres quedaban relegadas a las tareas de trabajo manual, mientras que los hombres se encargaban de las tareas mecánicas y de gestión. Así, entre las características de la fuerza de trabajo ocupada en la conserva destaca: a) su eventualidad, determinada por la estacionalidad de la producción; b) el predominio de mano de obra femenina, que representaba una fuente lucrativa de beneficios por su bajo coste salarial; c) y, por último, el escaso nivel de cualificación. Este sólo se incrementa a medida que se intensifica la mecanización y aumentan de tamaño las instalaciones fabriles.

La competitividad de la oferta española en los mercados internacionales no sólo se ha mantenido a lo largo del período analizado, sino que ha mejorado posiciones relativas. En torno a 1930, la pulpa de albaricoque, de variedad «búlida», producida en Murcia, conquista definitivamente el mercado europeo. En lo que a países mediterráneos se refiere, tan sólo en concentrados y purés de tomate mostraba ventaja la industria conservera italiana. Ahora bien, hay que resaltar que buena parte de la producción española, sobre todo la murciana, se destinaba a la industria reelaboradora en los países 
de destino. Esta rémora se mantiene hasta la década de 1970. En cuanto a la distribución, tampoco se constata la existencia de agrupaciones de exportadores, hecho que hubiera mantenido una posición más fuerte en los mercados internacionales. La dispersión de esfuerzos encaminados a la distribución del producto como consecuencia de la ausencia de asociaciones en la comercialización debió restar competitividad en el sector. No obstante, la distribución contaba con el apoyo y la experiencia exportadora de otros productos españoles: vinos, naranjas, frutas frescas, pimentón, entre otros, que habiendo penetrado en los mercados exteriores ya a finales del siglo xix aportaban, en algunos casos, sus propios canales y agentes en la comercialización de la conserva.

Observando la estructura de costes en la industria conservera murciana, las materias primas constituyen el capítulo más importante, entendiendo por tales las frutas y hortalizas, los envases metálicos y las cajas de madera, y en menor medida el azúcar. De esta última se ha visto su escaso empleo por su elevado precio y la alta protección arancelaria de que goza en todo el período. Más problemático ha sido, por su necesidad, el suministro de envases metálicos, sobre todo en los inicios. Ello, junto con la calidad de hojalata empleada, ha sido otra de las preocupaciones de los fabricantes. Salvo casos aislados en que se han dado situaciones conflictivas por escasez y fuerte subida de precios, los problemas de suministro se han ido resolviendo entre acuerdos por las dos partes: siderúrgicos y conserveros. A medida que se avanza en el curso del primer tercio del siglo xx, la mayoría de las fábricas disponían de talleres propios de hojalata para su abastecimiento. Sin embargo, los puntos más conflictivos se alcanzan entre agricultores e industriales de la conserva. La compra de la fruta, ya por peso a puerta de fábrica, ya en el árbol, con recolección por cuenta del fabricante, ha favorecido la mayoría de las veces los intereses de los conserveros. Ha de tenerse en cuenta que una paralización de la venta de la fruta recogida puede arruinar a los agricultores por ser productos perecederos. Ello ha obligado en muchas ocasiones a los agricultores a plegarse a las condiciones de compra impuestas por los industriales.

Por último, cabe señalar las conexiones que se establecen entre el sector de la conserva y el resto de la economía. Aunque resulta difícil cuantificar los efectos «hacia delante» y «hacia atrás», sin embargo, en algunos campos debieron ser muy significativos. En el ámbito de la producción industrial afectaron a la siguiente gama de artículos: envases metálicos, maderas, cartón y papel, maquinaria, combustible, materiales de construcción y reparación. Por el lado de la agricultura, la industria necesitó de aprovisionamiento abundante de materia prima. En este sentido, la expansión de los frutales de hueso desde finales del siglo xix tiene que ver bastante con el desarrollo de la conserva vegetal. Esta incrementó la oferta de la producción agrícola y amplió 
las zonas de regadío, pero también mejoró sus variedades y los sistemas de cultivo, e indirectamente incentivó el empleo de insumos industriales. En suma, la industria de conservas vegetales ahondó el proceso de especialización por el que atravesaba la agricultura de regadío desde finales del siglo pasado y contribuyó al crecimeinto económico de algunas regiones, como la murciana, que se apoyaban en la producción de bienes alimenticios.

\section{BIBLIOGRAFIA}

Azagra Ros, Joaquín (1982): «Noticia de la situación fabril valenciana a mediados del siglo XIX según las fuentes de origen fiscal», en Estudios dedicados a Juan Peset Aleixandre, Valencia, vol. I, pp. 185.198.

BENDER, A. E. (1985): «The nutritional importance of fruit and vegetables", en Oddy y Miller (eds.), pp. 134-147.

Biescas Ferrer, José Antonio (1984): «Rasgos específicos en la evolución de la industria azucarera en España a lo largo del primer tercio del siglo XXm, en García Delgado (ed.), España 1898-1936; estructuras y cambio, Madrid, Universidad Complutense.

Calatayud Giner, Salvador (1986): Agricultura y Capitalismo. El desarrollo agrario va. lenciano duranie la segunda mitad del siglo XIX: La Ribera del Xŕquer, Valencia, tesis doctoral inédita.

Carmona Badía, Xan (1985): «La industria conservera gallega, 1840-1905», Papeles de Economía Española, núm. 3, pp. 177-191.

Carreras, Albert (1985): "Las industrias de bienes de consumo en el siglo xix», Información Comercial Española, núm. 623, pp. 105-116.

- (1987): «La industria: atraso y modernización», en Nadal, Carreras y Sudrià (comps.), pp. 280-312.

Comín, Francisco (1987): «La economía española en el período de entreguerras, 1919. 1935n, en Nadal, Carreras y Sudrià (comps.), pp. 105-149.

Derry, T. K., y WILliams, Trevor I. (1977): Historia de la tecnologia, Madrid, Siglo XXI, vol. 3.

Fontana Lázaro, Josep, y Nadal, Jordi (1980): «España, 1814-1970», en Cipolla (ed.), Historia económica de Europa. Economias contemporáneas, 2, Barcelona, Ariel, pp. 95. 163.

Gallego Martínez, Domingo (1986): La producción ugraria de Alava, Navarra y La Rioja desde mediados del siglo XIX a 1935, Madrid, Universidad Complutense.

García Delgado, José Luis (1985): «La industrialización española en el primer tercio del siglo XX», en Historia de España por Ramón Menéndez Pidal. Tomo XXXVII. Los comienzos del siglo XX. La población, la economía y la sociedad, 1898-1931, Madrid, Espasa-Calpe, pp. 1-171.

Garrabou, Ramón (1985): Un fals dilema. Modernitat o endarreriment de l'agricultura va. lenciana, 1850-1900, Valencia, Instituciò Alfons el Magnànim.

Garrabou, Ramón; Barciela, Carlos, y Jiménez Blanco, J. I. (eds.) (1986): Historia agraria de la España contemporánea. 3. El fin de la agricultura tradicional (1900-1960), Barcelona, Crítica.

GuZMáN GIMÉNEZ, Ginés (1986): «La conservación de alimentos y la industria conservera murciana», en La Cámara de Comercio. Historia viva de Murcia, 1899-1986, Murcia, Cámara de Comercio, Industria y Navegación, pp. 193.225. 
Hernansíez, José María (1900): Notas sobre el tema Estado actual de la Agricultura en la Huerta de Murcia y Progresos de que es susceptible, Murcia, Imp. Heraldo de Murcia.

Jiménez Blanco, José Ignacio (1984): La producción agraria de Andalucía Oriental, 1875 1914, Madrid, Universidad Complutense.

- (1986 a): «Introducción. El nuevo rumbo del sector agrario español (1900-1936)», en Garrabou, Barciela y Jiménez Blanco (eds.), pp. 9-141.

- (1986 b): «La remolacha y los problemas de la industria azucarera en España, 18801914», en Garrabou, Barciela y Jiménez Blanco (eds.), pp. 280-316.

Martínez Carrión, José Miguel (1987): Desarroilo agrario y crecimiento económico en la región murciana, 1875-1935. Murcia, tesis doctoral inédita.

- (1988): «Cambio agrícola y desarrollo capitalista. El sector agrario murciano a finales del siglo XIX, 1875-1914», en Garrabou (ed.), La crisis agraria de fines del siglo XIX, Barcelona, Crítica, pp. 131-160.

- (s. f.): Agricultura $e$ Industria. El proceso de industrialización en la región murciana.

NADAL, Jordi (1987 a): «La industria fabril española en 1900. Una aproximación», en $\mathrm{Na}$ dal, Carreras y Sudrià (comps.), La economia española en el siglo XX. Una perspectiva bistórica, Barcelona, Ariel, pp. 23-61.

- (1987 b): «El desenvolupment de l'economia valenciana a la segona meitat del segle xIX: una via exclusivament agrària?", Recerques 19, Homenatge a Pierre Vilar. Vol. I, Barcelona, pp. 115-132.

Ochagavia, Diego (1955): «Conservas de La Rioja», en La industria conservera española, Madrid, Oficina de Estudios Económicos del Ministerio de Comercio, Madrid, pp. 83-87.

Oddy y Miller (eds.) (1985): Diet and Health in Modern Britain, Londres, Croom Helm.

Ortega Varcárcel, José (1986): Cantabria 1886-1986. Formación y desarrollo de una economia modernu, Santander, Cámara de Comercio, Industria y Navegación.

PAReja MuÑoz, Félix Luis (1957): Elementos de estructura económica de la industria conscrvera murciana. Directrices para su desarrollo económico, Murcia.

Prados de la Escosura, Leandro (1988): De imperio a nación. Crecimiento y alraso económico en España (1780-1930), Madrid, Alianza Editorial.

PUJOL ANDREU, Josep (1988): Les trans/ormacions del sector agrari catald̀ entre la crisis finisecular i la guerra civil, 1890-1936, Bellaterra, Universidad Autónoma de Barcelona.

Sánchez-Albornoz, Nicolás (ed.) (1985): La modernización económica de España, 18301930, Madrid, Alianza Editorial.

Seftel, Howard (1985): «Government Regulation and the Rise of the California Fruit Industry: the Entrepreneurial Attack on Fruit Pests, 1880-1920», Business History Review, 59, núm. 3, pp. 369-402.

Tortella Casares, Gabriel (1983): «Los problemas económicos de la II República», Revista de Estudios Políticos, núms. 31-32, pp. 121-135.

Zapata Blanco, Santiago (1986): La producción agraria de Extremadura y Andalucía Occidental, 1875.1935, Madrid, Universidad Complutense. 


\section{APENDICE ESTADISTICO}

\section{CUADRO 1}

Exportaciones de conservas vegetales, 1907-1935

\begin{tabular}{|c|c|c|c|}
\hline & A & B & C \\
\hline $\begin{array}{llllllll}1907 & \ldots & \ldots & \ldots & \ldots & \ldots & \ldots & \ldots \\
1908 & \ldots & \ldots & \ldots & \ldots & \ldots & \ldots & \ldots \\
1909 & \ldots & \ldots & \ldots & \ldots & \ldots & \ldots & \ldots \\
1910 & \ldots & \ldots & \ldots & \ldots & \ldots & \ldots & \ldots \\
1911 & \ldots & \ldots & \ldots & \ldots & \ldots & \ldots & \ldots \\
1912 & \ldots & \ldots & \ldots & \ldots & \ldots & \ldots & \ldots \\
1913 & \ldots & \ldots & \ldots & \ldots & \ldots & \ldots & \ldots \\
1914 & \ldots & \ldots & \ldots & \ldots & \ldots & \ldots & \ldots \\
1915 & \ldots & \ldots & \ldots & \ldots & \ldots & \ldots & \ldots \\
1916 & \ldots & \ldots & \ldots & \ldots & \ldots & \ldots & \ldots \\
1917 & \ldots & \ldots & \ldots & \ldots & \ldots & \ldots & \ldots \\
1918 & \ldots & \ldots & \ldots & \ldots & \ldots & \ldots & \ldots \\
1919 & \ldots & \ldots & \ldots & \ldots & \ldots & \ldots & \ldots \\
1920 & \ldots & \ldots & \ldots & \ldots & \ldots & \ldots & \ldots \\
1921 & \ldots & \ldots & \ldots & \ldots & \ldots & \ldots & \ldots \\
1922 & \ldots & \ldots & \ldots & \ldots & \ldots & \ldots & \ldots \\
1923 & \ldots & \ldots & \ldots & \ldots & \ldots & \ldots & \ldots \\
1924 & \ldots & \ldots & \ldots & \ldots & \ldots & \ldots & \ldots \\
1925 & \ldots & \ldots & \ldots & \ldots & \ldots & \ldots & \ldots \\
1926 & \ldots & \ldots & \ldots & \ldots & \ldots & \ldots & \ldots \\
1927 & \ldots & \ldots & \ldots & \ldots & \ldots & \ldots & \ldots \\
1928 & \ldots & \ldots & \ldots & \ldots & \ldots & \ldots & \ldots \\
1929 & \ldots & \ldots & \ldots & \ldots & \ldots & \ldots & \ldots \\
1930 & \ldots & \ldots & \ldots & \ldots & \ldots & \ldots & \ldots \\
1931 & \ldots & \ldots & \ldots & \ldots & \ldots & \ldots & \ldots \\
1932 & \ldots & \ldots & \ldots & \ldots & \ldots & \ldots & \ldots \\
1933 & \ldots & \ldots & \ldots & \ldots & \ldots & \ldots & \ldots \\
1934 & \ldots & \ldots & \ldots & \ldots & \ldots & \ldots & \ldots \\
1935 & \ldots & \ldots & \ldots & \ldots & \ldots & \ldots & \ldots\end{array}$ & $\begin{array}{r}37.232 \\
32.673 \\
37.631 \\
63.822 \\
60.780 \\
66.663 \\
72.238 \\
83.367 \\
151.030 \\
74.303 \\
66.218 \\
119.427 \\
204.486 \\
105.147 \\
167.264 \\
142.101 \\
119.929 \\
222.931 \\
182.622 \\
244.111 \\
244.232 \\
319.819 \\
305.168 \\
280.604 \\
293.190 \\
313.121 \\
237.168 \\
264.631 \\
260.067\end{array}$ & $\begin{array}{r}47.480 \\
51.887 \\
55.306 \\
72.167 \\
77.195 \\
93.377 \\
104.728 \\
73.243 \\
114.696 \\
128.854 \\
155.127 \\
88.793 \\
139.477 \\
102.682 \\
101.312 \\
111.482 \\
133.978 \\
163.617 \\
159.244 \\
159.782 \\
178.912 \\
160.875 \\
192.985 \\
159.173 \\
147.207 \\
208.734 \\
189.722 \\
172.256 \\
214.312\end{array}$ & $\begin{array}{r}27.475 \\
16.548 \\
16.058 \\
24.709 \\
25.924 \\
20.089 \\
24.943 \\
19.263 \\
30.225 \\
17.677 \\
13.603 \\
18.456 \\
42.844 \\
11.731 \\
14.556 \\
21.221 \\
6.452 \\
13.715 \\
15.544 \\
25.577 \\
14.342 \\
14.511 \\
21.492 \\
6.998 \\
2.039 \\
10.644 \\
33.324 \\
58.459 \\
81.210\end{array}$ \\
\hline
\end{tabular}

A: Pulpa de fruta.

B: Legumbres y hortalizas.

C: Frutas al natural en almíbar.

Fuente: Estadistica(s) del Comercio Exterior de España. 